\title{
Modelling and Mapping Elusive Locations of Historic Water- Powered Grist Mills
}

\author{
Michael E. Hodgson ${ }^{\mathrm{a}} *$, Silvia E. Piovan ${ }^{\mathrm{b}}$ \\ a Department of Geography, University of South Carolina, Columbia, SC (USA), hodgsonm@sc.edu \\ ${ }^{b}$ Department of Historical and Geographic Sciences and the Ancient World, University of Padova, Padova (Italy), \\ silvia.piovan@unipd.it \\ * Corresponding author
}

Keywords: Historic maps, confidence model, GIS, remote sensing.

\begin{abstract}
:
Grist mills are structures in which stone wheels are used to grind grain (e.g. corn, wheat) into a powder-like form for human consumption. Circular stone wheels provided the pressure to grind the grain and separate seed components. In most grist mills the energy for turning the heavy stones was derived from water power. The most visible part of some these mills was the externally mounted water wheel. However, other common configurations of the water 'turbine' internal to the structure were used (Figure 1). While grist mills existed in Europe at least as early as the $11^{\text {th }}$ century such mills were not present in the United States until the last 1600s. No comprehensive census has been conducted for grist mills in the U.S. although an estimate of all water powered mills in eastern U.S. was 65,000 in 1840 . Many of these water powered mills in the census estimate were for textile, sawmills, manufacturing, and other non-graingrinding applications.
\end{abstract}

Most often, the mill site included a small impoundment for creating a reliable source of water during low-flow stream conditions. These ponds were created in the late 1700s and especially in the 1800 s as a reliable water source for turning grist or saw mills. By the middle of the $20^{\text {th }}$ century the grist mills had all but vanished. Except for a few historic relics and conversion to touristic sites, the mill infrastructure has disappeared on the landscape while the mill ponds typically remain, serving other purposes, such as fishing or hunting lakes, or merely aesthetic environments.

The local ecosystems around the mills sites have been artificially modified by the presence of these stream impoundments providing a new environment for fish, mammals, avian species, and of course, humans. While numerous positive ecosystem values may be observed from their continued presence, the risk of dam failure to both downstream systems and humans is substantial. In fact, such a catastrophic series of dam failures (51 in South Carolina) occurred in October of 2015 from a heavy rainfall event. In other instances the impoundments now store toxic sediment originating from sources farther upstream such as mining, military or industrial processes.

Where are these historic mill sites and mill ponds? No inventory of mills or their ponds exist in South Carolina (and only for a few northeastern states). In this research we developed a systematic approach for identifying and mapping historic mill sites and ponds using a geohistorical framework and applied to South Carolina. The approach relied on 1) numerous geospatial sources, and 2) an analytical model of confidence mapping for predicting sites. The developed approach resulted in a new database of definitive and likely historic mill sites and mill pond locations throughout South Carolina. The sources of geospatial information was largely cartographic in nature including the following:

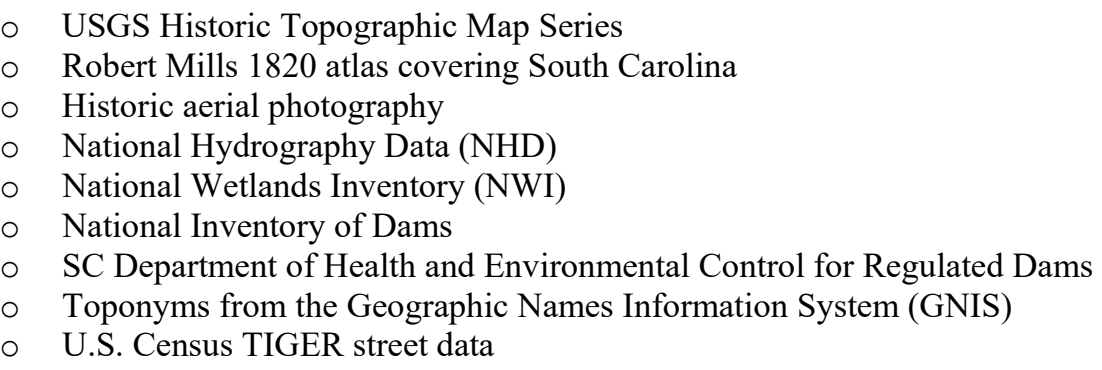

The design for a predictive model (Figure 2) using diverse historic data with various scales and reliability is problematic. Most of the grist mills have disappeared from the landscape and do not exist in contemporary geospatial databases. Historic maps might include toponyms for the sites or ponds but their map projection, scale, and subsequent distortions in geometry are problematic. In addition, some of the sources for data are derived from a similar source and thus, are not statistically independent. The design of the analytical model for mapping confidence in mill site locations was calibrated and subsequently validated using several independent sources of information. Numerous field visits to known and suspected locations for mills sites were conducted throughout the physiographic regions of South Carolina. 
The model of likelihood included factors for the reliability of the source, the mapping scale and spatial accuracy of the source, correlation with other sources, and likelihood of correspondence with grist mills.

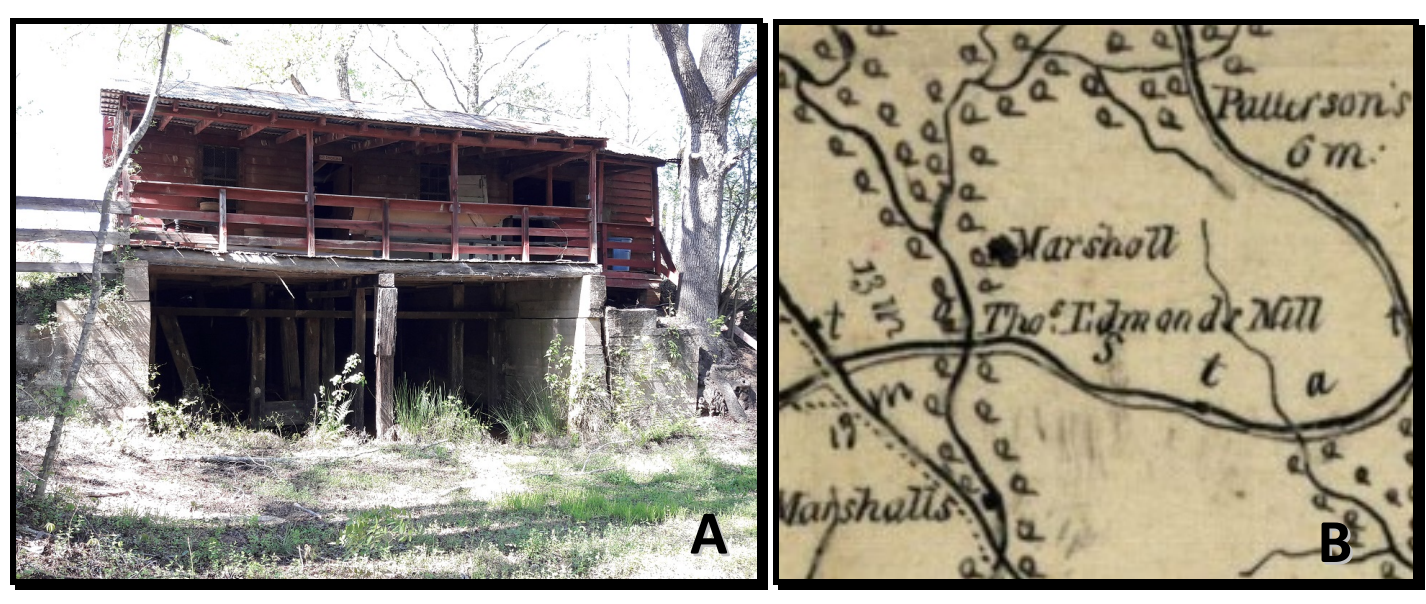

Figure 1. Edmond's mill (a water powered turbine mill) as existing in 2017 (a) and shown on the 1825 Atlas from Robert Mills in Richland County, S.C (b).

\section{Geodatabase of Mill and Mill Pond Sites}

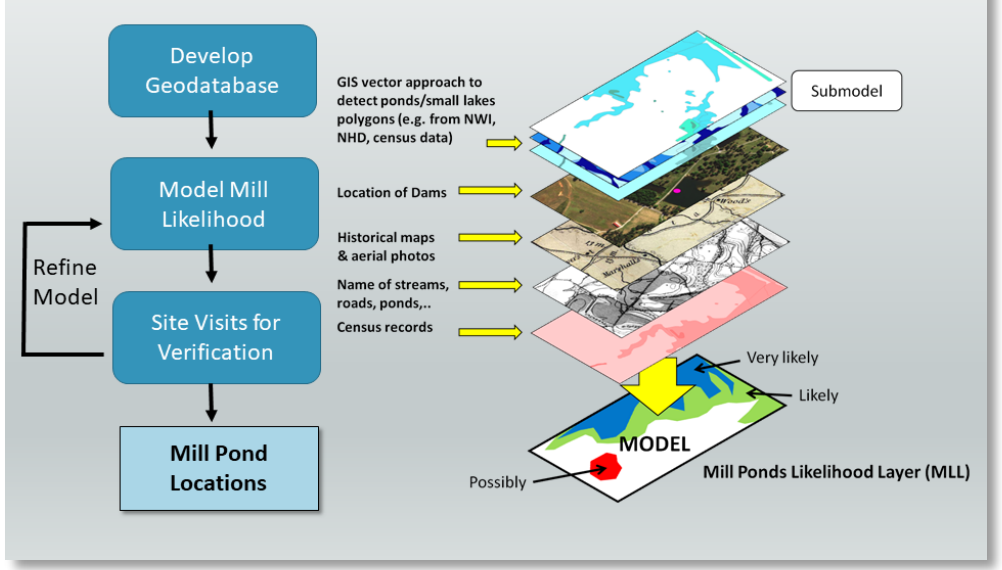

Figure 2. Grist mill and mill pond likelihood model. 